\title{
Motivation, self-efficacy, and student engagement in intermediate mechanical engineering courses
}

\section{Dr. Matthew J Ford, Cornell University}

Matthew Ford is currently a Postdoctoral Teaching Specialist working with the Cornell Active Learning Initiative. His background is in solid mechanics.

\section{Dr. Hadas Ritz, Cornell University}

Hadas Ritz is a senior lecturer in Mechanical and Aerospace Engineering, and a Faculty Teaching Fellow at the James McCormick Family Teaching Excellence Institute (MTEI) at Cornell University, where she received her $\mathrm{PhD}$ in Mechanical Engineering in 2008. Since then she has taught required and elective courses covering a wide range of topics in the undergraduate Mechanical Engineering curriculum. In her work with MTEI she co-leads teaching workshops for new faculty and assists with other teaching excellence initiatives. Her main teaching interests include solid mechanics and engineering mathematics.

\section{Prof. Elizabeth M. Fisher, Cornell University}

Elizabeth M. Fisher is an Associate Professor in the Sibley School of Mechanical and Aerospace Engineering at Cornell. She received her PhD from U.C. Berkeley. 


\title{
Motivation, self-efficacy, and student engagement in intermediate mechanical engineering courses
}

\begin{abstract}
Motivation is a critical component of student learning. Student motivation in the context of academic performance is composed of and influenced by several constructs such as intrinsic goals (learning for learning's sake), extrinsic goals (performance for the sake of a grade, career advancement, or other external validation), self-efficacy (confidence in one's ability to succeed with sufficient work), and value (belief that class activities are worthwhile). Much of the literature on motivation in engineering has focused on persistence beyond introductory courses, career choice, and differences between engineering majors. However, our interviews with mechanical engineering students have revealed that students may form motivational beliefs and identities related to a specific subfield within their major (e.g. "I see myself as a mechatronics person, but not a fluids person") and therefore we expect to find differences in responses between course contexts for the same student.

We measured motivation and attitudes towards learning in a cohort of students simultaneously enrolled in three upper-division mechanical engineering courses. We adapted portions of the Motivated Strategies for Learning Questionnaire (MSLQ) into two surveys: an online survey asking students to reflect on all of their mechanical engineering courses ("cohort context"), and a paper survey delivered during class in each of the three courses ("course context"). The cohort-context survey included questions related to intrinsic motivation and extrinsic motivation. The course-context surveys included questions related to intrinsic and extrinsic motivation, self-efficacy, study habits, task value, and peer learning. We also recorded measures of student engagement with course content including lecture attendance (proxied by a classroom polling system) and engagement with an online course discussion board.

Our unique study design allows us to examine the relationships between motivation, self-efficacy, engagement, and academic performance by comparing the same individual in different contexts rather than relying on group statistics. Extrinsic motivation was strongly correlated between courses. Intrinsic motivation, by contrast, was only weakly to moderately correlated between courses. Task value was not correlated between courses despite similar course formats and alignment with major requirements. Most surprisingly, self-efficacy was not correlated between courses, despite strong correlation of grades and exam scores. This curriculum-level lens provides valuable insights to guide the design of broad department-level educational initiatives.
\end{abstract}




\section{Introduction}

The present study is situated within a multi-year effort to transform the junior-year mechanical engineering curriculum at a private $\mathrm{R} 1$ university by developing active and inductive learning activities within large, primarily lecture-based courses. Because our project targets several courses simultaneously, and targets student motivation specifically, it is important to understand how motivational attitudes vary across courses.

Motivation is widely recognized as one of the most important factors in student success [1, 2, 3]. In classes using active learning pedagogies, it is important that students feel motivated and empowered to take charge of the process of knowledge creation and assimilation. Students may strive toward a variety of goals in an education context. Guided by mastery goals, students are motivated to build knowledge and master subject matter for its own value, rather than for the sake of a grade. Students who hold mastery goals are likely to invest heavily in the learning process and seek help when needed. Mastery goal orientation has been positively linked to perceived value of coursework, self-efficacy, and effective learning strategy use [4] and critical reflection [5]. Guided by performance goals, students are motivated to achieve high grades, especially for the sake of demonstrating their ability to others. Students who hold performance goals are likely to act strategically to maximize their performance and avoid challenges or risks that might present valuable learning opportunities. There is a wide range of similar overlapping constructs studied in the literature, but the broad distinction between mastery (or intrinsic) and performance (or extrinsic) goals is common to most theoretical frameworks. In practice, students hold multiple goals which simultaneously influence their approach to learning [3].

In addition to goal orientation, self-efficacy and task value are important facets of student motivation. Self-efficacy refers to a student's belief that they are capable of achieving a desired aim. Self-efficacy is influenced by prior successes, degree of support from the instructor, and appropriate difficulty of activities, amongst other factors [7]. Task Value in an educational context refers to a set of beliefs about "how interesting, useful, and important the course content is to the student." [6]. Task value is strongly connected to the particular activities and subject matter in a course. While self-efficacy is generally a stronger predictor of academic performance, high task value is associated with effort, persistence, and enrollment decisions [8, 9].

Motivation is an important feature in the Self-Regulated Learning (SRL) conceptual framework along with cognition, learning behaviors, and context [10]. A key assumption of the SRL perspective is that learners can exert some control over not only their behavior, but also their motivation, e.g. by positive self-talk, promising themselves extrinsic rewards, or connecting course-level goals with long-term career goals [10]. Our curriculum intervention strategy is based on the hypothesis that we can increase motivation by helping students make connections between activities and concepts in several required courses.

Motivational constructs are not fixed for a given student, but are assumed to depend on the particular learning context. The degree to which a student's attitudes vary between course contexts may depend on the details of the contexts as well as the age of the student. Bong measured motivational attitudes of Korean high school students in three subjects (Korean, English, and Math) as well as attitudes towards school generally and found that orientation towards performance goals were similar across subjects, while mastery goals, self-efficacy, value, 
and attributional beliefs (the belief that work leads to success) were only moderately or weakly correlated across subjects [11]. In an earlier study, Bong found that motivational attitudes were more clearly differentiated between subjects in high school students than in middle school students [12]. Wolters and Pintrich studied motivation and learning strategy use in middle school students and found similar patterns in variation of task value and self-efficacy across subjects [13], though learning strategy use was highly correlated between subjects. Motivation and self-efficacy in engineering students have been widely studied, especially in the context of understanding choice of major, persistence in the program of study, and engagement in active-learning contexts $[14,15,5,16,17,18]$. However, we were unable to find any studies of postsecondary engineering students which measured motivational constructs across multiple subjects for a given student.

These studies leave open the question of how motivational constructs may vary across subjects in adults who have self-selected into a narrow program of study and have progressed beyond the first two years in which motivation and identity are so important to persistence. Our study addresses this question by measuring motivational constructs in a cohort of mechanical engineering students multiple times across several different course contexts.

\section{Methods}

Data was collected from students in three concurrent Mechanical Engineering courses during the Fall 2019 semester ("Course A": Introductory Fluid Mechanics, "Course B": Mechanics of Materials, and "Course C": Mechatronics). These three courses have been targeted by our learning initiative because they reach every student enrolled in the mechanical engineering program (courses A and B are required while course $\mathrm{C}$ is taken by almost all students to satisfy a major requirement), and because we have identified opportunities for cross-cutting activities that connect material between these courses.

Students enrolled in any of the three courses were invited to participate in an online survey (the "cohort survey") during the third week of classes. For the cohort survey, we adapted questions from three subscales (intrinsic goal orientation, extrinsic goal orientation, and control of learning beliefs) of the Motivated Strategies for Learning Questionnaire [19]. We reworded each question to measure students' general attitudes towards their mechanical engineering courses by replacing the words "this class" with the words "my [mechanical engineering] courses." Only the first two subscales are analyzed in this study.

Students were then asked to complete a paper survey (the "course survey") during lecture in each of the three courses. The course surveys were administered during the eleventh and twelfth weeks of the semester. The course survey included questions from six subscales of the MSLQ: intrinsic goal orientation, extrinsic goal orientation, task value, self-efficacy for learning and performance, metacognitive self-regulation, and peer learning. Note that the MSLQ effectively combines task interest, task usefulness, and task importance into a single task value measure. Additionally, three questions about the perceived value of lecture time were added ("Lecture Value" questions are included in the Appendix). Each question asked students to identify with statements (e.g. "I like the subject matter of this course") on a seven-point Likert scale ranging from 1="not at all true of me" to $7=$ "very true of me." 
Table 1: Demographics of survey participants.

\begin{tabular}{lcccc}
\hline & & \multicolumn{3}{c}{ Course surveys } \\
\cline { 3 - 5 } & Cohort survey & $\mathrm{A}$ & $\mathrm{B}$ & $\mathrm{C}$ \\
\hline Number of students (participation rate) & $144(82 \%)$ & $74(60 \%)$ & $80(65 \%)$ & $116(78 \%)$ \\
Academic Level & & & & \\
$\quad$ Junior & $77 \%$ & $97 \%$ & $92 \%$ & $77 \%$ \\
$\quad$ Other & $23 \%$ & $3 \%$ & $8 \%$ & $23 \%$ \\
Gender & & & & \\
$\quad$ Man & $53 \%$ & $43 \%$ & $42 \%$ & $48 \%$ \\
$\quad$ Woman & $45 \%$ & $46 \%$ & $44 \%$ & $42 \%$ \\
$\quad$ Other/no response & $2 \%$ & $11 \%$ & $14 \%$ & $9 \%$ \\
Major & & & & \\
$\quad$ Mechanical Engineering & $83 \%$ & $93 \%$ & $96 \%$ & $85 \%$ \\
$\quad$ CS/ECE & $6 \%$ & $3 \%$ & - & $4 \%$ \\
$\quad$ Biomedical Engineering & $4 \%$ & - & - & $4 \%$ \\
$\quad$ Other & $6 \%$ & $4 \%$ & $4 \%$ & $6 \%$ \\
\hline${ }^{a}$ Electrical and Compury Engine
\end{tabular}

${ }^{a}$ Electrical and Computer Engineering

Due to the large number of surveys in the study, the total number of items was aggressively minimized by primarily focusing on the motivational constructs. The motivational subscales on the MSLQ were deemed more important than learning strategies for supporting the goals of the broader curriculum development project. Only two learning strategy subscales were used. Peer-learning was chosen because of its potential importance to planned curricular interventions involving team projects and small-group work. Metacognitive self-regulation was chosen because of the relatively high correlation with final grade reported by Pintrich, et. al. [19] and the importance of metacognition in active-learning settings. The metacognitive self-regulation subscale was further shortened from the original twelve questions to six, as recommended by Jackson [20].

In addition to surveys, we collected students' exam and course grades. Attendance was collected in each course using a classroom polling system (iClicker), though the data in Course A (Fluid Mechanics) was lost. All three courses used an online discussion platform (Piazza) to allow students to ask questions, which could be answered either by other students or by the course instructors. We collected summary statistics about students' participation on the platform including number of posts viewed and number of contributions. In some courses, students received a small amount of participation points towards their course grade for completing the surveys. The data collection and methods were approved by the Cornell Institutional Review Board under protocol \#1708007347.

\section{Results and discussion}

Out of 175 students enrolled in any of the three courses, 144 (82\%) took the cohort survey. Most students in the sample were junior mechanical engineering students (our primary target group). The sample of survey respondents was composed of $53 \%$ men and $45 \%$ women (2\% either marked another option or did not respond), which closely matches internal estimates of the demographics of the major, suggesting roughly equal participation rates. The students in Course 
Table 2: Summary statistics for affective measures and self-reported learning behaviors. The pvalue associated with a one-way ANOVA test of independence of means is given. All survey items have been adapted from [19] except for Lecture Value.

\begin{tabular}{|c|c|c|c|c|c|c|c|c|c|}
\hline \multirow[b]{2}{*}{ Variable } & \multicolumn{2}{|c|}{ Cohort } & \multicolumn{2}{|c|}{ Course A } & \multicolumn{2}{|c|}{ Course B } & \multicolumn{2}{|c|}{ Course C } & \multirow[b]{2}{*}{$p(>F)$} \\
\hline & mean & std & mean & std & mean & std & mean & std & \\
\hline Extrinsic Goal Orientation & 4.95 & 1.18 & 4.73 & 1.20 & 4.59 & 1.20 & 4.62 & 1.15 & 0.75 \\
\hline Intrinsic Goal Orientation & 5.26 & 0.97 & 4.78 & 1.23 & 4.60 & 1.02 & 4.85 & 0.98 & 0.28 \\
\hline Task Value & & & 5.48 & 1.21 & 5.13 & 1.29 & 5.57 & 0.97 & 0.02 \\
\hline Lecture Value & & & 4.85 & 1.42 & 4.69 & 1.34 & 5.27 & 1.07 & 0.004 \\
\hline Self-Efficacy & & & 4.67 & 1.33 & 4.98 & 1.26 & 4.70 & 1.19 & 0.21 \\
\hline Metacognitive Self-Regulation & & & 4.94 & 0.90 & 4.55 & 0.99 & 4.71 & 0.90 & 0.04 \\
\hline Peer Learning & & & 5.00 & 1.44 & 4.30 & 1.51 & 4.34 & 1.39 & 0.003 \\
\hline
\end{tabular}

All variables are measured on a 7-point Likert scale.

C (Mechatronics) who are not juniors are roughly evenly split between sophomores, seniors, and graduate students. 102 students $(58 \%)$ were co-enrolled in all three courses. Of these students, 47 completed the cohort survey and all three course surveys.

We confirmed the construct validity of the cohort survey using exploratory factor analysis (EFA) without relying on a priori assumptions about the underlying structure. In this case EFA is preferred over confirmatory factor analysis (CFA) because our modification of the wording of the original scale items and change in context of the survey can potentially impact the instrument validity. See [21] for a tutorial on factor analysis in the context of survey validation. The twelve MSLQ items in the cohort survey have a strong three-factor structure consistent with the underlying theory proposed by Pintrich et. al. [19]. (A third subscale, control of learning beliefs, was included in the survey and in the EFA, but is not discussed in this study). Four- and five-factor models were also investigated. Adding additional factors only split existing factors and did not result in any cross-scale loadings greater than 0.4 . The three-factor solution extracts $49 \%$ of the variance, vs. $51 \%$ for the four-factor solution. Identical analysis on the course survey supports a seven-factor solution corresponding closely to the seven subscales included. The additional questions regarding usefulness of attending lecture loaded onto a distinct factor from task value. Given this evidence, we will henceforth use the scale mean as a measure of each construct.

Descriptive statistics are given in Table 2. A one-way ANOVA was performed on each variable to determine whether group means varied significantly between course contexts. The $p$-value associated with the test is shown in the rightmost column. Four variables showed significantly different means between courses: task value, lecture value, metacognitive self-regulation, and peer learning. In each case the maximum difference was less than 0.5 standard deviations.

Tables 3 and 4 show between-course correlations of each measured variable, as well as within-course correlations with course outcomes and behavioral measures. Within-course, between-construct correlations are not shown.

Time is a confounding variable in our study, as the cohort survey was given near the beginning of the semester while the course surveys were given near the end. It is likely that at least some of the variation between the cohort and course contexts is due to timing. Therefore we cannot draw any 
Table 3: Correlations (between-courses) for motivational constructs, and correlations (withincourse) with course outcomes and student behaviors. "Views" is the number of posts the student viewed on the online discussion platform (Piazza).

\begin{tabular}{|c|c|c|c|c|c|c|c|c|}
\hline \multirow[b]{2}{*}{ Variable } & \multicolumn{4}{|c|}{ Between-course correlations } & \multicolumn{2}{|c|}{ Outcomes } & \multicolumn{2}{|c|}{ Behaviors } \\
\hline & A & B & $\mathrm{C}$ & General & Exam & Grade & Attendance & Views \\
\hline \multicolumn{9}{|c|}{ Extrinsic Goal Orientation } \\
\hline Course A & 1 & $0.81 * * *$ & $0.77 * * *$ & $0.66^{* * *}$ & -0.17 & -0.15 & - & 0.09 \\
\hline Course B & & 1 & $0.75^{* * * *}$ & $0.72 * * *$ & 0.09 & 0.20 & $0.23 *$ & $0.24 *$ \\
\hline Course C & & & 1 & $0.67 * * *$ & -0.05 & 0.05 & 0.02 & 0.05 \\
\hline \multicolumn{9}{|c|}{ Intrinsic Goal Orientation } \\
\hline Course A & 1 & $0.38 * *$ & $0.52 * * *$ & $0.52 * * *$ & 0.09 & 0.11 & - & 0.10 \\
\hline Course B & & 1 & $0.27 *$ & $0.34 * *$ & 0.03 & 0.09 & 0.09 & $0.28 *$ \\
\hline Course C & & & 1 & $0.55 * * *$ & 0.26 & 0.16 & $0.24 *$ & -0.11 \\
\hline \multicolumn{9}{|l|}{ Task Value } \\
\hline Course A & 1 & 0.25 & 0.01 & & -0.04 & 0.04 & - & -0.02 \\
\hline Course B & & 1 & $-0.25 *$ & & 0.18 & $0.32 * *$ & $0.25^{*}$ & $0.19^{\dagger}$ \\
\hline Course C & & & 1 & & $0.41 * *$ & 0.12 & $0.18^{*}$ & $-0.18^{\dagger}$ \\
\hline \multicolumn{9}{|l|}{ Lecture Value } \\
\hline Course A & 1 & -0.15 & $0.34 * *$ & & -0.13 & -0.13 & - & -0.12 \\
\hline Course B & & 1 & $0.33 * *$ & & 0.04 & 0.16 & $0.42^{* * *}$ & $0.28 *$ \\
\hline Course C & & & 1 & & -0.03 & 0.01 & $0.24 * *$ & 0.00 \\
\hline \multicolumn{9}{|l|}{ Self-Efficacy } \\
\hline Course A & 1 & $0.27 *$ & 0.14 & & 0.03 & 0.10 & - & 0.01 \\
\hline Course B & & 1 & 0.01 & & $0.25^{*}$ & $0.42 * * *$ & 0.18 & $0.37 * * *$ \\
\hline Course C & & & 1 & & $0.51 * * *$ & $0.41 * * *$ & $0.17^{\dagger}$ & -0.08 \\
\hline
\end{tabular}

conclusions about the mean differences between goal orientations measured at the cohort and course level.

\section{Motivational constructs}

Extrinsic goal orientation was strongly correlated between contexts $(0.75<r<0.81)$, as well as between course context and cohort context, consistent with prior work [12,11]. The consistency of this relationship in very different populations and educational settings suggests that orientation towards performance goals is not as sensitive to contextual factors. Intrinsic goal orientation is only moderately correlated between contexts and with general attitude, and there is considerable variation in correlations depending on the particular subjects compared $(0.27<r<0.52)$. Discussing the lack of between-course correlation of intrinsic goals in high school students compared with middle school subjects, Bong suggested that students' increasing concern with choosing a college major may explain the increasing specialization [12]. One might speculate that this variation should therefore disappear after students have self-selected into a major; however our results showed the opposite trend. It is possible that by the junior year, students interests are increasingly tied to specific career aspirations, leading them to value specific subjects more strongly.

We found no evidence for correlations between task value across courses $(-0.25<r<0.25$, not 
significant when correcting for number of comparisons), consistent with Bong's findings in high school students [12]. Nevertheless, within courses, there are consistent, highly-significant $(p<0.001)$ correlations between task value and intrinsic goal orientation $(0.59<r<0.72)$ and between task value and self-efficacy $(0.57<r<0.68)$. Task value is intimately connected to the subject matter, assignments, and projects in each course and is therefore context-specific. Lecture value (the subjective value students assign to the activities during class time) was moderately correlated with task value within courses $(0.32<r<0.53)$.

Surprisingly, academic self-efficacy was similarly uncorrelated between course contexts $(0.01<r<0.27$, not significant when correcting for number of comparisons). The variation is especially surprising given the fact that the course surveys were given late in the semester when a student might be able to accurately forecast their final grade, and final course grades were strongly intercorrelated $(0.66<r<0.75)$. In other words, although students earned similar grades in these courses less than a month after completing the course survey, they rated their ability to succeed significantly differently from course to course. The questions on the self-efficacy scale used in this study [19] explicitly relate to course grade as a measure of performance (e.g. "I believe I will receive an excellent grade in this class.")

In contrast, Bong [12] found correlations in self-efficacy ranging from 0.24 to 0.63 between contexts for high school and middle school students. However, Bong noted in the same study that while self-efficacy of middle school students in four subjects was consistent with a model parameterized by a single "general" self-efficacy construct, self-efficacy of high-school students in four subjects was more consistent with two independent constructs representing self-efficacy in verbal and quantitative subjects. Our data is consistent with a general trend of students developing more differentiated self-efficacy beliefs as they progress academically.

The relationship between affective measures and course outcomes were not consistent across the three courses. Self-efficacy was correlated with final exam score $(0.25<r<0.51)$ and course grade $(0.41<r<0.42)$ in courses B (Mechanics of Materials) and C (Mechatronics), but not in course A (Fluid Mechanics). Course format was broadly similar across all three courses in terms of class size, lecture style, and in-class activities, although Course B had a lab and Course $\mathrm{C}$ had a multi-week project. There were some differences in assessments: Course A had a unique oral midterm exam and Course $\mathrm{C}$ had an optional final exam. We have no specific hypothesis to explain the surprising lack of correlation between self-efficacy and grades in Course A.

\section{Learning strategies}

The two learning strategies scales (metacognitive self-regulation and peer learning) were moderately and consistently correlated across courses $(0.47<r<0.55$ and $0.54<r<0.68$, respectively). Furthermore, there was a moderate within-course correlation between metacognitive self-regulation and peer learning in all three courses $(0.32<r<0.48$, $p<0.001)$.

Lecture attendance rate was positively correlated with task value, lecture value, and peer learning. All three courses incorporated partner and small group discussions into lecture through Think-Pair-Share activities [22] and occasional group problem solving. It is possible that students who are willing to work with peers value lecture time more highly, especially in active-learning 
Table 4: Between-course and selected within-course correlations for learning strategies.

\begin{tabular}{|c|c|c|c|c|c|c|c|}
\hline \multirow[b]{2}{*}{ Variable } & \multicolumn{3}{|c|}{ Between-course correlations } & \multicolumn{2}{|c|}{ Outcomes } & \multicolumn{2}{|c|}{ Behaviors } \\
\hline & A & B & $\mathrm{C}$ & Exam & Grade & Attendance & Views \\
\hline \multicolumn{8}{|c|}{ Metacog. Self-Regulation } \\
\hline Course A & 1 & $0.47 * * *$ & $0.55^{* * *}$ & -0.05 & 0.04 & - & 0.02 \\
\hline Course B & & 1 & $0.47^{* * *}$ & -0.04 & 0.09 & 0.17 & $0.21^{\dagger}$ \\
\hline Course C & & & 1 & 0.17 & 0.15 & $0.20^{*}$ & 0.03 \\
\hline \multicolumn{8}{|l|}{ Peer Learning } \\
\hline Course A & 1 & $0.54 * * *$ & $0.62^{* * *}$ & $0.21^{\dagger}$ & $0.20^{\dagger}$ & - & 0.02 \\
\hline Course B & & 1 & $0.68 * * *$ & $0.20^{\dagger}$ & $0.30 * *$ & $0.33 * *$ & $0.22^{\dagger}$ \\
\hline Course C & & & 1 & 0.25 & $0.19 *$ & $0.26 * *$ & 0.00 \\
\hline
\end{tabular}

settings. Course $\mathrm{C}$ (Mechatronics) showed a positive correlation between lecture attendance and intrinsic goal orientation. The last several weeks of Mechatronics are mostly devoted to a large group project and lecture content moves to advanced content which is not directly applicable to the project. The final exam, which includes this content, is optional and used to drop the lowest midterm score.

There were no consistent trends across courses relating motivational constructs to use of the online discussion platform. Only course B (Mechanics of Materials) showed weak to moderate (but statistically significant) correlations between goal orientation, lecture value, and self-efficacy and number of posts viewed on the platform. Instructors used the platform for both content-related discussion and administrative announcements, and the differences in instructors' use of the platform make it difficult to rely on this metric for between-course comparisons.

Although the focus of this paper is not on the link between behavioral measures and course outcomes, we observed that lecture attendance was a positive predictor of course grade, even when controlling for grade in a pre-requisite course. Number of online discussion platform views was weakly to moderately correlated with final grade, but was not a significant predictor when controlling for attendance and pre-requisite grade.

\section{Conclusion}

Mechanical engineering students' attitudes and approaches to learning depend to varying degrees on the course context in which they are measured. Consistent with prior studies in younger students $[12,11]$, extrinsic goal orientation was strongly correlated both across course contexts and with a general-context measure (in this case, "my mechanical engineering courses"), while intrinsic goal orientation was moderately correlated across course contexts. Task value, which is tightly bound to the specific topics and activities of a course showed weak or nonexistent between-course correlations. Surprisingly, academic self-efficacy also varied significantly between courses, in contrast with results in younger students [12,13]. Learning strategies (metacognitive self-regulation and peer-learning) and lecture attendance were moderately correlated between courses.

There are opportunities to increase students' motivation to learn by making connections between 
activities and concepts in different courses. We found that intrinsic goal orientation is more variable than extrinsic goal orientation, and that task value varies significantly between courses. If students perceive the usefulness of applying concepts from a course in which they have little intrinsic interest in a class for which they have high intrinsic interest, they may find it more worthwhile to invest effort they would not otherwise feel motivated to invest. A major thrust of our teaching initiative is to develop cross-cutting examples and projects which combine content and concepts from co-requisite courses.

Although the three courses studied are all primarily lecture-based, large-enrollment courses, they differ considerably in instructor teaching style, types of assignments, format of exams, grading policy, and teaching assistant support. It is impossible to draw conclusions from our quantitative data about the relationship between features of each course and the variation in student attitudes. Many of the questions raised in this study would be best answered through qualitative data including interviews and focus groups. It is not clear, for example, why students form such distinct feelings of self-efficacy despite the strong correlation between course grades. Such qualitative methods are beyond the scope of this study, but will be explored in the future.

\section{References}

[1] S. A. Ambrose, M. W. Bridges, M. DiPietro, M. C. Lovett, and M. K. Norman, How Learning Works. Jossey-Bass, 2010.

[2] A. Wigfield and J. S. Eccles, "Expectancy-value theory of achievement motivation," Contemporary Educational Psychology, vol. 25, no. 1, pp. 68-81, 2000.

[3] P. R. Pintrich, "Multiple goals, multiple pathways: The role of goal orientation in learning and achievement," Journal of Educational Psychology, vol. 92, no. 3, pp. 544-555, 2000.

[4] C. A. Wolters, S. L. Yu, and P. R. Pintrich, "The relation between goal orientation and students' motivational beliefs and self-regulated learning," Learning and Individual Differences, vol. 8, no. 3, pp. 211-238, 1996.

[5] D. Heo, S. Anwar, and M. Menekse, "The relationship between engineering students' Achievement goals, reflection behaviors, and learning outcomes," International Journal of Engineering Education, vol. 34, no. 5, pp. 1634-1643, 2018.

[6] T. G. Duncan and W. J. Mckeachie, "The Making of the Motivated Strategies for Learning Questionnaire," Educational Psychologist, vol. 40, no. 2, pp. 117-128, 2005.

[7] M. Ponton, J. Edmister, L. Ukeiley, and J. Seiner, "Understanding the Role of Self-Efficacy in Engineering Education," Journal of Engineering Education, no. April, pp. 247-252, 2001.

[8] M. Bong, "Role of self-efficacy and task-value in predicting college students' course performance and future enrollment intentions," Contemporary Educational Psychology, vol. 26, no. 4, pp. 553-570, 2001.

[9] J. S. Cole, D. A. Bergin, and T. A. Whittaker, "Predicting student achievement for low stakes tests with effort and task value," Contemporary Educational Psychology, vol. 33, no. 4, pp. 609-624, 2008.

[10] P. R. Pintrich, “A conceptual framework for assessing motivation and self-regulated learning in college students,” Educational Psychology Review, vol. 16, no. 4, pp. 385-407, 2004.

[11] M. Bong, "Academic Motivation in Self-Efficacy, Task Value, Achievement Goal Orientations, and Attributional Beliefs,” Journal of Educational Research, vol. 97, no. 6, pp. 287-298, 2004. 
[12] M. Bong, "Between- and within-domain relations of academic motivation among middle and high school students: Self-efficacy, task-value, and achievement goals," Journal of Educational Psychology, vol. 93, no. 1, pp. 23-34, 2001.

[13] C. A. Wolters and P. R. Pintrich, "Contextual differences in student motivation and self-regulated learning in mathematics, English, and social studies classrooms," Instructional Science, vol. 26, pp. 27-47, 1998.

[14] B. D. Jones, M. C. Paretti, S. F. Hein, and T. W. Knott, "An analysis of motivation constructs with first-year engineering students: Relationships among expectancies, values, achievement, and career plans," Journal of Engineering Education, vol. 99, no. 4, pp. 319-336, 2010.

[15] H. M. Matusovich, R. A. Streveler, and R. L. Miller, "Why do students choose engineering? A qualitative, longitudinal investigation of students' motivational values," Journal of Engineering Education, vol. 99, no. 4, pp. 289-303, 2010.

[16] O. Lawanto, "Understanding the Correlation between Goal Orientation and Self-Efficacy for Learning and Performance in an Engineering Design Activity in Grades 9-12," American Society of Engineering Education Zone IV Conference, pp. 355-362, 2010.

[17] N. A. Mamaril, E. L. Usher, C. R. Li, D. R. Economy, and M. S. Kennedy, "Measuring Undergraduate Students' Engineering Self-Efficacy: A Validation Study,” Journal of Engineering Education, vol. 105, no. 2, pp. 366-395, 2016.

[18] R. M. Marra and T. Wheeler, "Impact of an authentic, student-centered engineering project on student motivation," Proceedings - Frontiers in Education Conference, vol. 2, pp. 8-13, 2000.

[19] P. R. Pintrich, D. A. F. Smith, T. Garcia, and W. J. McKeachie, "A Manual for the Use of the Motivated Strategies for Learning Questionnaire (MSLQ)," tech. rep., National Center for Research to Improve Postsecondary Teaching and Learning, Ann Arbor, MI, 1991.

[20] C. R. Jackson, "Validating and Adapting the Motivated Strategies for Learning Questionnaire (MSLQ) for STEM Courses at an HBCU," AERA Open, vol. 4, no. 4, pp. 1-16, 2018.

[21] E. Knekta, C. Runyon, and S. Eddy, "One size doesn't fit all: Using factor analysis to gather validity evidence when using surveys in your research,” CBE Life Sciences Education, vol. 18, no. 1, pp. 1-17, 2019.

[22] E. Mazur, Peer Instruction: A User's Manual. Upper Saddle River, NJ: Prentice Hall, 1996. 


\section{Appendix: Surveys}

Table 5: Cohort survey items. The complete cohort survey included other questions not discussed in this paper.

\begin{tabular}{|c|c|c|}
\hline Item & Subscale & Question \\
\hline 3 & IGO & $\begin{array}{l}\text { The most satisfying thing for me in my MAE courses is trying to understand the content as } \\
\text { thoroughly as possible. }\end{array}$ \\
\hline 6 & IGO & $\begin{array}{l}\text { When I have the opportunity in my MAE courses, I choose course assignments that I can learn } \\
\text { from even if they don't guarantee a good grade. }\end{array}$ \\
\hline 8 & IGO & In my MAE courses, I prefer material that arouses my curiosity, even if it is difficult to learn. \\
\hline 11 & IGO & In my MAE courses, I prefer material that really challenges me so I can learn new things. \\
\hline 1 & EGO & Getting a good grade in my MAE courses is the most satisfying thing for me right now. \\
\hline 5 & EGO & $\begin{array}{l}\text { The most important thing for me right now is improving my overall grade point average, so my } \\
\text { main concern in my MAE courses is getting a good grade. }\end{array}$ \\
\hline 7 & EGO & If I can, I want to get better grades in $m y$ MAE courses than most of the other students. \\
\hline 10 & EGO & $\begin{array}{l}\text { I want to do well in my MAE courses because it is important to show my ability to my family, } \\
\text { friends, employer, or others. }\end{array}$ \\
\hline 2 & CLB & If I try hard enough, then I will understand the material taught in my MAE courses. \\
\hline 4 & CLB & $\begin{array}{l}\text { If I don't understand the material taught in my MAE courses, it is because I didn't try hard } \\
\text { enough. }\end{array}$ \\
\hline 9 & CLB & It is my own fault if I don't learn the material in my MAE courses. \\
\hline 12 & CLB & If I study in appropriate ways, then I will be able to learn the material in my MAE courses. \\
\hline
\end{tabular}

IGO=Intrinsic Goal Orientation, EGO=Extrinsic Goal Orientation, CLB=Control of Learning Beliefs.

Items adapted from [19]. Changes indicated in italics. 
Table 6: Course survey items.

\begin{tabular}{|c|c|c|}
\hline Item & Subscale & Question \\
\hline 5 & EGO & $\begin{array}{l}\text { The most important thing for me right now is improving my overall grade point average, so my } \\
\text { main concern in this class is getting a good grade. }\end{array}$ \\
\hline 13 & EGO & $\begin{array}{l}\text { I want to do well in this class because it is important to show my ability to my family, friends, } \\
\text { employer, or others. }\end{array}$ \\
\hline 23 & EGO & Getting a good grade in this class is the most satisfying thing for me right now. \\
\hline 29 & EGO & If I can, I want to get better grades in this class than most of the other students. \\
\hline 8 & IGO & $\begin{array}{l}\text { When I have the opportunity in this class, I choose course assignments that I can learn from } \\
\text { even if they don't guarantee a good grade. }\end{array}$ \\
\hline 24 & IGO & $\begin{array}{l}\text { In a class like this, I prefer course material that arouses my curiosity, even if it is difficult to } \\
\text { learn }\end{array}$ \\
\hline 30 & IGO & In a class like this, I prefer course material that really challenges me so I can learn new things \\
\hline 33 & IGO & $\begin{array}{l}\text { The most satisfying thing for me in this course is trying to understand the content as thoroughly } \\
\text { as possible }\end{array}$ \\
\hline 2 & TV & I like the subject matter of this course \\
\hline 3 & TV & I think I will be able to use what I learn in this course in other courses \\
\hline 9 & TV & It is important for me to learn the course material in this class. \\
\hline 17 & TV & Understanding the subject matter of this course is very important to me. \\
\hline 26 & $\mathrm{TV}$ & I think the course material in this class is useful for me to learn. \\
\hline 28 & TV & I am very interested in the content area of this course. \\
\hline 22 & $\mathrm{LV}$ & aluable \\
\hline 27 & LV & $\begin{array}{l}\text { I think I learn more in lecture for this class than from out-of-class readings or multimedia (video } \\
\text { etc.) material. }\end{array}$ \\
\hline 31 & LV & In this class, I don't feel that I really learn anything new in lecture. (Reverse coded) \\
\hline 6 & SE & I'm certain I can understand the most difficult material presented in the readings for this course \\
\hline 7 & SE & I'm confident I can do an excellent job on the assignments and tests in this course \\
\hline 11 & SE & I believe I will receive an excellent grade in this class \\
\hline 18 & SE & I'm confident I can learn the basic concepts taught in this course \\
\hline 19 & SE & $\begin{array}{l}\text { Considering the difficulty of this course, the teacher, and my skills, I think I will do well in this } \\
\text { class }\end{array}$ \\
\hline 25 & SE & I'm certain I can master the skills being taught in this class \\
\hline 32 & SE & I expect to do well in this class \\
\hline 34 & SE & $\begin{array}{l}\text { I'm confident I can understand the most complex material presented by the instructor in this } \\
\text { course }\end{array}$ \\
\hline 1 & MSR & I ask myself questions to make sure I understand the material I have been studying in this class \\
\hline 12 & MSR & $\begin{array}{l}\text { When I become confused about something I'm reading for this class, I go back and try to figure } \\
\text { it out }\end{array}$ \\
\hline 14 & MSR & Before I study new course material thoroughly, I often skim it to see how it is organized \\
\hline 16 & MSR & When studying for this course I try to determine which concepts I don't understand well \\
\hline 20 & MSR & $\begin{array}{l}\text { When I study for this class, I set goals for myself in order to direct my activities in each study } \\
\text { period. }\end{array}$ \\
\hline 21 & MSR & If course readings are difficult to understand, I change the way I read the material \\
\hline 4 & PL & When studying for this course, I often try to explain the material to a classmate or friend \\
\hline 10 & PL & $\begin{array}{l}\text { When studying for this course, I often set aside time to discuss course material with a group of } \\
\text { students from the class }\end{array}$ \\
\hline 15 & PL & I try to work with other students from this class to complete the course assignments \\
\hline
\end{tabular}

